\title{
educação revista

\section{Educação Ambiental no Brasil: reflexões a partir da Década da Educação para o Desenvolvimento Sustentável das Nações Unidas (2005-2014)}

Environmental Education in Brazil: reflections from the Decade of Education for Sustainable Development of the United Nations (20052014)

Carlos Eduardo Marques da Silva

Universidade de Pernambuco, Recife, Pernambuco, Brasil. cadumarques81@gmail.com

Simone Ferreira Teixeira

Universidade de Pernambuco, Recife, Pernambuco, Brasil.

teixeirasf.upe@gmail.com - https://orcid.org/0000-0001-9759-9651

Recebido em 03 de janeiro de 2019

Aprovado em 28 de junho de 2019

Publicado em 09 de outubro de 2019

\section{RESUMO}

A Educação Ambiental tem sido apontada como caminho para concretização de formas renovadas na relação homem-ambiente diante dos graves problemas sociais e ambientais da atualidade. Buscou-se refletir sua institucionalização a partir da Década da Educação para o Desenvolvimento Sustentável, no intuito de identificar e caracterizar a atenção dedicada à consolidação de uma Educação orientada para os princípios da Sustentabilidade, no Brasil. O artigo constitui-se num levantamento bibliográfico-documental, e procura refletir como os preceitos instituídos como pertinentes a uma Educação para o Desenvolvimento Sustentável tem se consubstanciado na realidade brasileira, discutindo questões relativas à sua institucionalização, internalização nos currículos escolares e financiamento público. Verifica-se, a despeito da larga produção acadêmica e institucional, que tal educação permanece marginal e secundária na realidade brasileira.

Palavras-chave: Políticas Públicas; Educação; Sustentabilidade 


\section{Autuaŗão}

ISSN: 1984-6444 | http://dx.doi.org/10.5902/1984644436261

\section{ABSTRACT}

Environmental Education has been pointed as a way to materialize renewed forms in the human-environment relationship in the face of today's serious social and environmental problems. It was sought to reflect its institutionalization from the Decade of Education for Sustainable Development, in order to identify and characterize the attention dedicated to the consolidation of an Education oriented to the principles of Sustainability in Brazil. The article is a bibliographical-documentary survey and seeks to reflect how the precepts instituted as pertinent to an Education for Sustainable Development have been embodied in the Brazilian reality, discussing issues related to its institutionalization, internalization in school curricula and public funding. It is verified, despite the large academic and institutional production, that such education remains marginal and secondary in the Brazilian reality.

Keywords: Public Policy; Education; Sustainability.

\section{Introdução}

Desde o fim da Guerra Fria, os questionamentos quanto à continuidade do modelo de desenvolvimento adotado pela humanidade vêm se avolumando no mundo. Inicialmente apontada pelos ecologistas, a busca por um modelo alternativo de desenvolvimento vem sendo disseminada desde a década de 60 , compreensão consubstanciada no Relatório Brundtland (1987) e pauta de Conferências Mundiais do Meio Ambiente, entre elas a Rio-92 e Rio +20 (2012). A população mundial tem vivido fora dos limites renováveis do planeta, e a busca por modelos que mantenham o desenvolvimento de modo sustentável tem ocorrido desde então, com abordagens contrastantes e até contraditórias, dados os interesses conflitantes dos atores envolvidos (MARTINE; ALVES, 2015; PEREIRA; ROCHA, 2015; DINIZ; BERMANN, 2012).

Não pretendendo ingressar na celeuma conceitual que envolve a temática, consideramos aqui a exigência de uma atuação para o equilíbrio entre as dimensões ambiental, econômica e social, incorporando a noção de igualdade ou equidade entre humanidade e ambiente, entre as pessoas e entre as gerações, para definir um desenvolvimento sustentável. Podemos resgatar nesta perspectiva os princípios ou valores da sustentabilidade indicados ainda em 1986 por Sachs: a satisfação das necessidades básicas; a solidariedade com as gerações futuras; a participação da 


\section{Authabูão}

ISSN: 1984-6444 | http://dx.doi.org/10.5902/1984644436261

população envolvida; a conservação dos recursos naturais e do meio ambiente em geral; a elaboração de um sistema social que garanta emprego, segurança e respeito a outras culturas; e a elaboração de programas de educação.

É crescente o reconhecimento internacional da importância da Educação para o Desenvolvimento Sustentável (EDS) como um elemento integrante da educação de qualidade e essencial para a sustentabilidade socioambiental. Contudo, articular as categorias institucionais da Educação e do Desenvolvimento Sustentável exige a participação de todos os atores sociais envolvidos, e uma essencial sensibilização dos dirigentes governamentais e gestores organizacionais, a fim de que estabeleçam condições para que a educação esteja orientada para o alcance de seus fins últimos, e a serviço da construção de um convívio social mais justo, equilibrado e saudável.

Buscamos caracterizar a Educação Ambiental/Educação para o Desenvolvimento Sustentável, refletindo a atenção a esta dedicada no Brasil, em especial a partir da Década da Educação para o Desenvolvimento Sustentável. Questionando se as demandas por mudanças de comportamento em prol da sociedade e do meio ambiente estão conduzindo a um repensar da educação, discutimos aspectos relacionados ao seu papel na prática e seu alcance na realidade social do país, evidenciados em pesquisas e práticas pedagógicas, e a possibilidade do alcance de mudanças comportamentais e para a criticidade dos sujeitos.

\section{Metodologia}

Realizamos um levantamento bibliográfico, nas bases de dados Scientific Library Online (Scielo), Periódicos Eletrônicos em Psicologia (PePsic), Literatura Latino-americana e do Caribe em Ciências da Saúde (LILACS - BVS), Index Psi e Periódicos da CAPES, complementada com alguns trabalhos localizados no Google Acadêmico. Buscamos publicações em periódicos científicos, entre os anos de 2007 e 2017, e usamos como método a busca em "todos os índices", para se ter uma maior amplitude de resultados, com uso de aspas na formatação dos termos pesquisados, por serem compostos. 


\section{Ej|lिa \\ ISSN: $1984-6444$

ISSN: 1984-6444 | http://dx.doi.org/10.5902/1984644436261

Os critérios de inclusão dos artigos foram: a) artigos que relacionassem ações desenvolvidas no (ou propostas para o) Brasil; b) que possuíssem nos títulos, palavras-chave e/ou nos resumos a nomeação Educação Ambiental ou Educação para o Desenvolvimento Sustentável, e revelassem relações entre estes construtos em seu escopo; c) artigos que não se repetissem; d) artigos disponíveis para consulta; e, e) artigos publicados em periódicos científicos.

\section{Resultados e discussão}

\section{Uma Educação para o Desenvolvimento Sustentável}

Alcançar a sustentabilidade requer um processo de mudança de valores estruturais, numa visão essencialmente de longo prazo. De fato, não se concebe outro caminho possível para se superar os dois maiores problemas da humanidade para este século: o caos ecológico e a desigualdade global profunda (MARTINE; ALVES, 2015).

Se o que se procura é uma mudança de paradigmas pautada em novos valores, consciência e atitudes, nenhum destes objetivos pode ser alcançado sem considerar seriamente a educação. De modo geral, a educação é apontada como um processo de desenvolvimento integral das potencialidades do indivíduo, estimulando o aprendiz para que, propiciando sua autotransformação, desenvolva as faculdades necessárias para integrar-se plenamente à sociedade (CIAVATTA, 2005; SAVIANI, 2007). Em sua ação, a educação tanto forma os indivíduos quanto é formada por estes, numa relação dialógica, de construção mútua capaz de reproduzir e refletir os valores culturais estruturantes da realidade social.

Desde a Rio 92, a educação é vista como instrumento fundamental para o alcance da sustentabilidade mundial. Esta tomada de consciência levou boa parte dos Estados-membros da Organização das Nações Unidas a adotar, em 2000, os oito Objetivos do Milênio para o Desenvolvimento Sustentável - os ODM (a serem trabalhados no período de 2000 a 2015) - e ao estabelecimento da Agenda 2030 para o Desenvolvimento Sustentável - esta contendo dezessete objetivos, a serem 


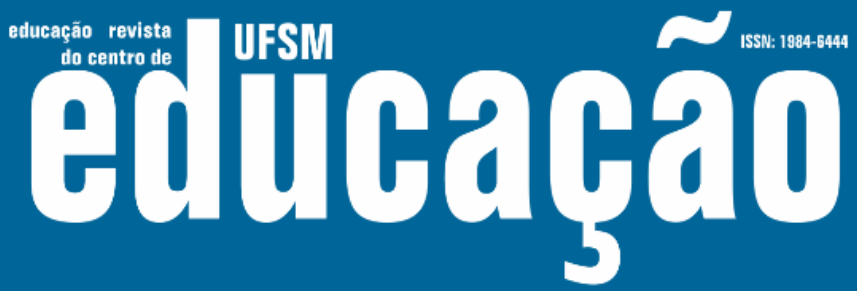

ISSN: 1984-6444 | http://dx.doi.org/10.5902/1984644436261

trabalhados no intervalo de 2015 a 2030 - (ONU, 2015). Seus objetivos e metas se propõem a estimular transformações em áreas cruciais para a prosperidade da humanidade e do planeta, num plano de ação que se diz ambicioso e busca concretizar os direitos humanos integrados às diferentes dimensões do desenvolvimento sustentável. A Educação figura em todos estes projetos, sendo fundamental para a criação de condições para o alcance dos objetivos propostos, nascendo daí a noção de uma Educação para o Desenvolvimento Sustentável - EDS.

A EDS é destacada pelas Nações Unidas como categoria específica, emergindo como uma dimensão que deve ser estimulada em todos os níveis educacionais e por todos os países, integrada às políticas educacionais e práticas educativas, alinhada aos propósitos libertadores que a educação em si representa. Estaria pautada no envolvimento de todos os atores do processo de educação (formal ou não-formal) de forma interdisciplinar, objetivando a tomada de consciência de nossa relação com as pessoas, a natureza e o mundo, desenvolvendo o pensamento crítico e habilidades para a busca por soluções para enfrentamento dos desafios da atualidade, incentivando o diálogo e a solidariedade para a promoção do respeito e convívio harmônico com os outros e com meio ambiente natural e social, criando autonomia com a oferta de conhecimentos, competências e valores que tornem os indivíduos agentes da mudança (UNESCO, 2005; GADOTTI, 2008; FREITAS, 2006; BASTOS; DE SOUZA LEMES, 2015).

Novamente, encontra-se uma multiplicidade de divergências sobre que educação e que pedagogias são adequadas ao contexto, dadas as diferenças conceituais e instrumentais implicadas em posições que ora refutam-se entre si, como no embate entre EDS e Educação Ambiental (EA), no qual alguns segmentos consideram questionável o conceito de Desenvolvimento Sustentável, enxergando nele um viés de apologia ao economicismo e uma vinculação com as forças do mercado, ora se apoiando mutuamente, como propõe Gadotti (2005, p. 242) ao apresentar a chamada Pedagogia da Práxis, em diálogo com a ecopedagogia, e com a EDS, caracterizando-as como uma nova visão da realidade formativa, que se volta "a reeducar o olhar (...), desenvolver a atitude de perceber e não ficar indiferente 


\section{T usm eltubarao

ISSN: 1984-6444 | http://dx.doi.org/10.5902/1984644436261

diante das agressões ao meio ambiente" transformando os indivíduos em cidadãos planetários.

A Organização das Nações Unidas para a Educação, a Ciência e a Cultura (UNESCO) compreende uma diferenciação entre os campos da EA e EDS, apontando a segunda como um maior espectro, que englobaria a EA posicionando-a num contexto mais amplo de questões sociais, políticas e culturais (UNESCO, 2005), diferenciação que não teve eco na realidade brasileira, onde prevalece o conceito da Educação Ambiental, cujos defensores indicam uma tendência maior à busca por uma "sociedade sustentável" do que para um "desenvolvimento sustentável" (GÓMEZ, 2005; PÉREZ; LLORENTE, 2005).

Aqui adotamos a posição de FREITAS (2006):

De igual forma, não vemos que o debate "educação para o desenvolvimento sustentável" versus "educação ambiental" materialize o confronto entre uma visão "economicista" e uma visão "política" de educação ou, sequer, esgote o encontro/confronto de perspectivas educativas que se preocupam com a construção de um futuro melhor. Cada uma das duas perspectivas em discussão (EA e EDS) inclui uma diversidade de tendências, apoiadas não só numa ou outra das perspectivas a que se aludiu, mas também numa infinidade de cambiantes e recombinantes dessas perspectivas. (FREITAS, 2006, p. 6).

Sem reduzir a importância de situar conceitualmente a compreensão destas categorias, aqui nos debruçamos especialmente em reconhecer: há um papel a ser desempenhado pela educação em prol da sustentabilidade universal? As demandas por mudanças de comportamento em prol da sociedade e do meio ambiente estão conduzindo a um repensar da educação? As práticas educativas que se propõem sustentáveis apontam para propostas pedagógicas voltadas ao desenvolvimento da criticidade dos sujeitos? Uma educação que responda positivamente para estas questões, está na nossa compreensão de uma Educação para o Desenvolvimento Sustentável.

O reconhecimento da educação e de sua importância enquanto instrumento de transformação levou a ONU a proclamar a Década das Nações Unidas da Educação para o Desenvolvimento Sustentável (DEDS) para o período de 2005-2014, tendo a UNESCO como agência selecionada para dinamizar junto aos Estados-membros, sua 


\section{HEM oltuaráo

ISSN: 1984-6444 | http://dx.doi.org/10.5902/1984644436261

integração em todos os níveis da administração pública, incentivando os países a repensar sua educação, seus programas escolares e suas práticas pedagógicas.

A estratégia proposta pela UNESCO (2005) no Esquema de aplicação internacional (tradução nossa) para a DEDS, tendo foco no estabelecimento de parcerias sinérgicas na sociedade em todos os seus níveis, apontava como objetivos: a) facilitar a ligação em rede, ligações, intercâmbio e interação entre partes interessadas na ESD; b) promover uma maior qualidade de ensino e aprendizagem na Educação para desenvolvimento sustentável; c) ajudar os países a progredir e alcançar os objetivos do milênio pelos esforços da EDS; d) proporcionar aos países novas oportunidades para incorporar os esforços da EDS na reforma educacional. Contudo, reconhecendo as disparidades regionais entre os países, conclamava os Estados-Membros para avançar, também, na melhoria do acesso e qualidade da Educação Básica, na reorientação dos programas de ensino existentes, e para o treinamento e desenvolvimento da conscientização e compreensão pública.

A nova visão da educação na verdade representa um redirecionamento mundial da educação, num esforço fundamentado na cooperação, na integração comunitária, na reorientação das políticas e sistemas nacionais de educação, fomentando redes e parcerias para a concretização de seus objetivos e ações na sociedade.

\section{A Educação para o Desenvolvimento Sustentável no Brasil}

O acolhimento da terminologia da EDS no Brasil não ocorreu pacificamente, pelas divergentes compreensões que o termo introduz, mantendo-se a denominação de Educação Ambiental, dado o conjunto de estruturas e processos políticoinstitucionais que veio se consolidando no país há aproximadamente 30 anos, supostamente orientados para os mesmos aspectos propositivos da EDS, conforme fundamenta as Diretrizes Curriculares Nacionais (BRASIL, 2013), segundo as quais:

\footnotetext{
"...na tradição da Educação Ambiental brasileira e latino-americana (o termo) não é empregado para especificar um tipo de educação, mas constitui-se em elemento estruturante que demarca um campo político de valores e práticas, mobilizando atores sociais comprometidos com a prática político- pedagógica transformadora e emancipatória capaz de promover a ética e a cidadania ambiental". (BRASIL, 2013, p. 515).
} 


\section{F HEM Gutirahá}

ISSN: 1984-6444 | http://dx.doi.org/10.5902/1984644436261

Resultado direto da interdisciplinaridade inerente ao campo da sustentabilidade, a aproximação de pensadores de diferentes setores inevitavelmente recaiu sobre a orientação não apenas conceitual, mas ideológica e até política desta educação, e tais disputas acabaram por declinar conceitualmente da EDS, ratificando o conceito de Educação Ambiental.

Considerando então o desenvolvimento da Educação Ambiental e seus desdobramentos para a formação e pedagogia no país, apontamos três questões, que nos parecem fundamentais para compreender o impacto da Educação Ambiental no processo educacional: a) a institucionalização da Educação Ambiental; b) a penetração insuficiente nos programas curriculares nacionais e os problemas da qualidade da educação nacional; c) o financiamento à Educação ambiental.

\section{Como vem se institucionalizando a Educação Ambiental no Brasil?}

Nos últimos anos a Educação Ambiental passou por um amplo processo de institucionalização formal. As questões ambientais vêm sendo observadas desde a Política Nacional do Meio Ambiente (BRASIL, 1981) e na Constituição Federal (BRASIL, 1988), que institui um Sistema Nacional do Meio Ambiente e o Conselho Nacional do Meio Ambiente. Uma Política Nacional de Educação Ambiental (PNEA) surge em 1999, fazendo eco às demandas apontadas na Rio 92, trazendo regulamentações, diretrizes, princípios e objetivos que vão somar-se às novas estratégias político-institucionais para a Educação Ambiental no Brasil.

No nível federal é criado um Órgão Gestor da Política Nacional de Educação Ambiental, instância intermediária entre o Ministério da Educação e o Ministério do Meio Ambiente, para impulsionar as ações voltada à Educação Ambiental, tanto no viés formal quanto na educação não-formal. Este teria o papel de contribuir para a transformação dos professores em educadores ambientais, capazes de disseminar valores e conhecimentos quanto à sustentabilidade e à participação dos alunos e comunidade nos projetos e ações de Educação Ambiental (BRASIL, 2005).

A PNEA chama Estados e Municípios para definir suas diretrizes e normas relativas à Educação Ambiental, possibilitando a desconcentração e contextualização 


\section{ON WFH olturaná

ISSN: 1984-6444 | http://dx.doi.org/10.5902/1984644436261

dos programas, projetos e atividades em Educação Ambiental (LEMOS; NETO; XAVIER, 2017). São criadas Comissões Estaduais Interinstitucionais de Educação Ambiental, responsáveis pela formulação de políticas estaduais para a educação ambiental. Também surgem Redes de Educação Ambiental, agregando pessoas e instituições, e realizando eventos e atividades articuladas em torno do tema.

Porém, se, por um lado, é notória a institucionalização pública formal da Educação Ambiental, ainda são evidenciadas diversas fragilidades no campo políticoinstitucional, dentre as quais Layrargues (2012) aponta:

- baixa qualificação profissional entre alguns quadros técnicos dos gestores governamentais e de membros das instâncias colegiadas;

- fraca representatividade de membros nas instâncias colegiadas;

- descontinuidades políticas na sucessão entre as distintas gestões governamentais;

- elaboração de programas de educação ambiental instrumentalizados pela pauta do ambientalismo pragmático, gerando insatisfações;

- refluxo nas redes de educação ambiental, alternando períodos efervescentes de atividades com outros de total apatia e imobilismo;

- conflitos de gestão e representatividade das redes, pautadas na horizontalidade e multiliderança, junto às instâncias colegiadas, de organização social vertical e hierarquizada;

- redes para a Educação Ambiental atuando como reprodutoras de interesses particulares; e,

- frágil diálogo para fora do círculo dos educadores ambientais, envolvendo outros atores sociais, notadamente os movimentos populares e sociais.

Tais aspectos resultam em enfraquecimento prático (e político) das instâncias relativas à EA e das ações educativas, contribuindo, como é comum nos sistemas jurídico-normativos brasileiro, para um avanço normativo e institucional, parcamente enraizado na sociedade, resultando mais em dominação e direcionamento das orientações vigentes do que numa mudança de paradigmas. 


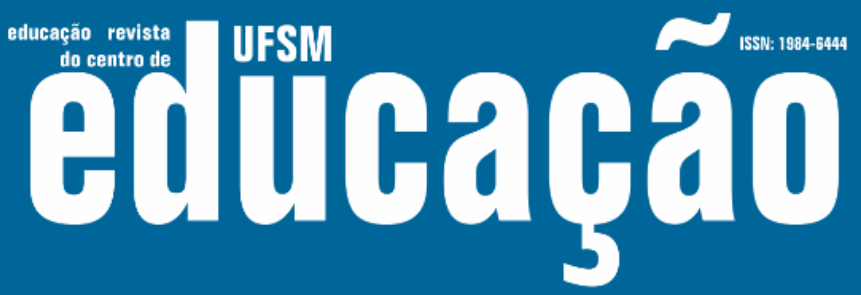

ISSN: 1984-6444 | http://dx.doi.org/10.5902/1984644436261

\section{Como a Educação Ambiental se insere nos programas de ensino?}

Conforme as proposições da UNESCO (2005) para a EDS, o conceito de desenvolvimento sustentável deveria somar-se aos currículos escolares, envolvendo professores, alunos, pais e comunidades, e associando a educação formal e a educação não-formal, com a comunidade interna e externa da escola discutindo e construindo o tema em projetos-político-pedagógicos que vinculem educação e sustentabilidade. Porém a inserção legal da EA no ensino não resultou de fato em incorporação aos projetos político-pedagógicos nem na dinâmica escolar.

O termo "Educação Ambiental" não aparece na Lei 13.005/2014, nem entre as metas do Plano Nacional de Educação, com o termo "desenvolvimento sustentável" e "sustentabilidade" vagamente citado em apenas em um momento. Na Lei de Diretrizes e Bases da Educação Nacional, Lei no 9.394/96, o único ponto a falar sobre a Educação Ambiental foi revogado ( $§ 7^{\circ}$ do art. 26). A referência à EDS no ensino formal é deveras circunstancial, o que se repete também no texto base da recente Base Nacional Comum Curricular (BRASIL, 2015).

Vai aparecer de fato nas Diretrizes Curriculares Nacionais (DCN), onde já de início se indica que a Educação Ambiental deve superar "práticas educacionais muitas vezes reducionistas, fragmentadas e unilaterais da problemática ambiental, e abordagem despolitizada e ingênua dessa temática" (DCN, 2013, p. 522), abordandoa de modo processual, continuada e incremental, para todos os níveis e modalidades de ensino. Porém estabelece apenas que sua inserção nos currículos ocorrerá transversalmente, ou como conteúdo de uma disciplina já constante do currículo, o que sugere baixa relevância dispensada à temática na prática, deixando de prescrever princípios e diretrizes operacionais e pedagógicas, concorrendo para que sejam negligenciados ou subsumidos sem cumprir o papel que deveriam ter na formação dos sujeitos.

É o que se observa ao analisar os parâmetros curriculares do Estado de Pernambuco, onde a Educação Ambiental passa praticamente despercebida, surgindo pontualmente apenas nos currículos dos componentes relacionados às ciências naturais, e maciçamente vinculado às questões ambientais, escusando os 


\title{
TH Wu Eutloapga
}

ISSN: 1984-6444 | http://dx.doi.org/10.5902/1984644436261

problemas sociais intrínsecos, os aspectos heurísticos, a visão holística, da integralidade e da promoção de consciência crítica dos estudantes para a temática.

Analogamente, avaliando a penetração da EDS nas ações educativas e institucionais do governo de São Paulo, Bastos e De Souza Lemes (2015) verificam insignificante repercussão nas políticas educacionais, denunciando que o comprometimento com a DEDS por parte do governo de São Paulo teria ficado muito aquém das expectativas, pouco se reproduzindo nos ciclos plurianuais de aprendizagem e conscientização, não encontrando nos conteúdos dos currículos oficiais qualquer menção à DEDS ou à EDS.

\begin{abstract}
...percebe-se que, tanto a DEDS como a EDS, não foram evidenciadas, de forma contundente, pelas políticas educacionais do governo paulista durante o percurso decenal estabelecido pela ONU para a DEDS... (BASTOS; DE SOUZA LEMES, 2017, p.181).

...constatar que em nenhum momento a Agenda 21 foi levada em consideração no contexto curricular, já seria motivo suficiente para fundamentar tal inferência. BASTOS; DE SOUZA LEMES, 2017, p. 183).
\end{abstract}

Se para a DEDS tais temas deveriam ter centralidade estruturante na Educação, no Brasil parece não ter movimentado os programas de ensino. Parece que a falta de sensibilidade dos tomadores de decisão para incluí-la nos currículos se fortalece com os conhecidos obstáculos e problemas de que padece a educação nacional (problemas de gestão escolar, carga horária x extensão curricular, carreira docente, etc.) além da baixa capacitação dos professores e das problemáticas relacionadas à qualidade das intervenções pedagógicas no ensino público.

Camboim e Barbosa (2012) também evidenciam como fragilidades da $E A$, a falta de comprometimento da comunidade escolar para o sucesso das estratégias pedagógicas em gestão ambiental, falta de ações interdisciplinares, e de uma abordagem crítica para professores e alunos, incentivando-os à autonomia e à tomada de decisão, recaindo nas velhas representações reducionistas ou utilitaristas do Meio Ambiente.

Pesquisa voltada a analisar práticas pedagógicas fundamentadas na Educação para o Desenvolvimento Sustentável no ensino de Ciências no Brasil e em Portugal (DA CUNHA SANTOS; SILVA; PEDROSA, 2016) evidencia como limitações práticas: 


\section{F HEM eutuarao

ISSN: 1984-6444 | http://dx.doi.org/10.5902/1984644436261

burocracia de diferentes ordens; contrato temporário da maioria dos professores de ciências, o que inviabiliza a continuidade dos projetos; os extensos programas de ciências a serem cumpridos; ausência do envolvimento coletivo da comunidade escolar; ausência de tempo e espaço de estudos; e, escassos recursos didáticos para introduzir temas relacionados à ciência, tecnologia, sociedade e questões ambientais no ensino. Ou seja, mesmo entre os professores em ciências naturais, cujos componentes curriculares pressupõem (insatisfatoriamente) a temática da sustentabilidade ambiental de algum modo, as dificuldades práticas da realidade escolar obstaculizam suas intervenções.

Para atingir seus fins, a Educação Ambiental deve ser encarada em seu sentido mais amplo, significando dar conotação totalmente nova às suas ações, sendo conteúdo perene nas práticas educativas, o que requer mudança de posicionamento de toda a comunidade escolar, pais, professores, gestores, mas principalmente das instâncias destinadas a pensar e formular planos e práticas de ensino.

\section{E o orçamento para a Educação Ambiental?}

No entendimento dos governantes brasileiros, a Educação Ambiental deveria ser construída a partir de um corpus independente do sistema nacional de educação, mantendo conexões e diálogos entre si, mas coexistindo como instâncias em separado, para a condução de suas ações conforme as políticas formuladas, tendo como finalidade a materialização da Lei no 9.795/1999. Para isto, conforme a Lei 9.795, criou-se um órgão gestor para a Política Nacional de Educação Ambiental, formado por representantes dos Ministérios da Educação e do Meio Ambiente. Contudo, a própria Lei 9.795 não estabelece fonte específica de financiamento para as ações de Educação Ambiental que, tidas como ações perenes, deveriam perpassar todas as disciplinas em todos os níveis e modalidades da educação formal, de modo permanente. Era de se esperar que uma construção que já tem duas décadas pudesse dispor de alocação de recursos proporcional à sua importância no cenário nacional, mas as ações em EA parecem, para os dirigentes governamentais, não necessitar de financiamentos e incentivos além daqueles já destinados aos programas específicos 


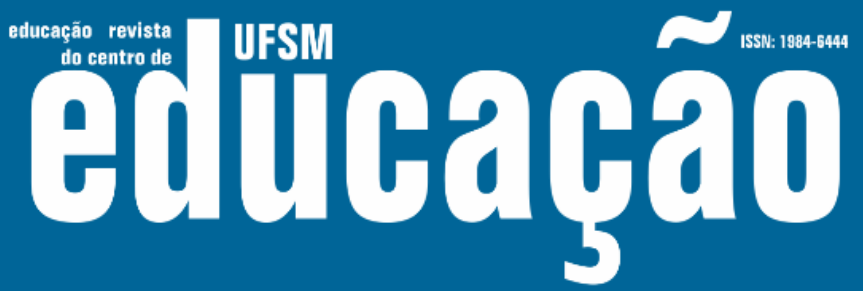

ISSN: 1984-6444 | http://dx.doi.org/10.5902/1984644436261

dos respectivos Ministérios, aos quais a EA emerge mais na forma de apêndice do que de categoria estruturante. Não por acaso, o artigo 18, único artigo da Lei 9.795 que previa fonte de recursos para financiamento das ações de Educação Ambiental, terminou por ser vetado.

Nesta esteira, e ampliando a precariedade de sua efetividade prática, desde o Impeachment da Presidenta Dilma Rousseff, em 2016, o governo interino e o presidente eleito têm expressado cada vez menos preocupação com a sustentabilidade e as questões sociais e ambientais. Sua agenda desenvolvimentista, de orientação neoliberal, tem resultado no enfraquecimento das restrições para licenciamento ambiental de empreendimentos econômicos, flexibilização do Código Florestal, posicionamentos políticos favoráveis a ruralistas e a ocupantes ilegais de terras protegidas, ameaças de retirar o país de acordos internacionais de preservação ambiental, apontando para a redução de áreas de preservação ambiental ou destinadas a comunidades tradicionais. Ações que expressam uma visão retrógrada e evidência da pouca importância com que os governantes têm tratado as questões socioambientais no país, dentre as quais, a Educação Ambiental figura como uma das mais fragilizadas.

De fato, pesquisando o Plano Plurianual federal para o período de 2016 a 2019, encontram-se apenas 07 (sete) entradas para o termo Educação Ambiental, relacionados a quatro programas de governo. Um destes, o programa "Educação de qualidade para todos" de responsabilidade do Ministério da Educação, na verdade representa o conjunto de ações gerais voltadas para a educação; o programa Promoção dos direitos da juventude, da Presidência da República, mas vinculado a um objetivo de responsabilidade do Ministério do Meio Ambiente; o programa de "Qualidade ambiental", que na verdade trata-se de uma ação parte da Política Nacional de Resíduos Sólidos; e como parte do "Bolsa Verde".

Enfim, no tocante ao financiamento federal para a Educação Ambiental, transparece que, apesar de todos os termos edificantes das diretrizes, princípios e objetivos regulamentados na PNEA, nas Diretrizes Curriculares Nacionais para a Educação e no Programa Nacional de Educação Ambiental proposto, a descrição de tão essencial política como um constante exercício de transversalidade (BRASIL, 


\section{Ism elturarao}

ISSN: 1984-6444 | http://dx.doi.org/10.5902/1984644436261

2013) acaba sendo outra forma de dizê-la complementar e acessória. Na realidade educacional brasileira, a despeito dos esforços dos educadores, a Educação Ambiental ainda ocupa um lugar marginal.

\section{Algumas considerações}

De acordo com a UNESCO, as escolas deveriam funcionar como laboratórios de sustentabilidade, transformadas em polos de incorporação e difusão dos valores do Desenvolvimento Sustentável, mobilizando a sociedade para vivenciar uma cultura de cidadania e participação ativa, uma vez que a escola deve ser, por excelência, um lugar para aprendizagem e cidadania. Contudo, fica evidente a posição marginal ocupada pela Educação Ambiental no Brasil, em contraposição à centralidade proposta pela UNESCO para a Década da Educação para o Desenvolvimento Sustentável.

A institucionalização não é garantia de aplicação social daqueles conteúdos, salvo quando há previsão de sanção legal em seu descumprimento. É o que se observa quando a PNEA é regulamentada indicando diretrizes e objetivos a serem alcançados, sem versar sobre imputações pecuniárias para os órgãos envolvidos que deixarem de executá-la. Entendemos que tais fins só podem ser alcançados no longo prazo, mas ainda é mínima a preocupação com a EA na sociedade atual, quando esta deveria ser uma categoria fundamental para a edificação moral do sujeito humano, e a não-obrigatoriedade de sua imputação às vivências cotidianas revela uma penetração aquém da construção teórica e institucional até então formulada.

Parece que as disputas políticas, ideológicas e teóricas acabaram fazendo com que o Brasil perdesse a oportunidade de reafirmar-se como liderança no tema, uma liderança para além de conteúdos normativos, formalmente avançados e progressistas, mas de pífia eficácia social, muito aquém do necessário para surtir as reais transformações que a sociedade brasileira necessita. A partir destas questões, compreendemos como, segundo Layrargues (2012), a Década das Nações Unidas da Educação para o Desenvolvimento Sustentável passou praticamente despercebida no país. 


\section{Authabูão}

ISSN: 1984-6444 | http://dx.doi.org/10.5902/1984644436261

Concordamos com a noção de que sua temática deva ser tratada interdisciplinarmente e transversalmente, em todas as modalidades e formas de educação do país. Contudo, sabemos que culturalmente a educação tradicional encontra dificuldades em trazer os temas transversais para a sala de aula, amparada por uma cultura educativa didaticamente ultrapassada, pela extensão dos conteúdos obrigatórios dos componentes curriculares, pelos problemas estruturais das profissões dos trabalhadores da Educação no Brasil, aliada à baixa instrumentalização e capacitação da maioria dos profissionais em Educação, carentes eles próprios da formação requerida para despertar a visão crítica sobre o Desenvolvimento Sustentável que deveriam propiciar aos seus alunos. No caso da EA, também parece ampliar este paradigma o fato de que as ações deste campo não partem nem privilegiam o corpo educacional em sua formulação. Os educadores deveriam ser conclamados para fomentar esta construção, mas muitas vezes são postas por profissionais ou entidades externas à prática do sistema educacional.

Tais fatores concorrem para uma internalização cultural insatisfatória dos Parâmetros Curriculares Nacionais na escola, fazendo com que os temas transversais ocupem posição secundária nas propostas de ensino, concretizadas em ações pontuais, reducionistas e esvaziadas. A recente aprovação da Base Nacional Curricular Comum para o ensino fundamental, apontando para a exclusão da obrigatoriedade no envolvimento de todos os temas transversais nos planos de ensino, dentre os quais figura a EA, concorre para o esvaziamento da percepção crítica de suas questões nas salas de aula.

Os professores que, a despeito das dificuldades, buscam o aperfeiçoamento de suas práticas pedagógicas e as revestem de formas didáticas renovadas e atuais, esbarram em problemas burocráticos, no individualismo estrutural que se reflete na grande dificuldade da atuação interdisciplinar, na falta de comprometimento da comunidade escolar resultante da baixa disseminação social da relevância do tema, na falta de recursos para realização prática de suas atividades, que impossibilita a continuidade dos projetos. E os próprios parâmetros curriculares tratam a EA por um viés naturalista, de forma esvaziada e reducionista, sem aludir ao processo da DEDS, 


\section{TH Wu Eutoraba}

ISSN: 1984-6444 | http://dx.doi.org/10.5902/1984644436261

cujo mote poderia ter servido para que tal movimento ganhasse expressão significativa, ampliando seu alcance social.

A luta da Educação para o Desenvolvimento Sustentável tem longo caminho pela frente, especialmente sabendo-se que o direito à educação ainda não foi universalizado em diversas partes do mundo, emergindo ainda entre os Objetivos do Desenvolvimento Sustentável na Agenda 2030 (ONU, 2015 - Objetivo 4, s/p.) a necessidade de "assegurar a educação inclusiva e equitativa e de qualidade, e promover oportunidades de aprendizagem ao longo da vida para todos".

Tanto quanto implantar a educação como direito universal, é preciso reorientála, transformando-a em espaço de inserção do indivíduo numa comunidade local que é sistematicamente global, mobilizando toda a sociedade numa grande rede estratégica, capaz de dinamizar processos de mudança que se esperam significativos no contexto de uma EDS, e que só será eficaz com a cooperação das diversas instituições sociais, nos diversos níveis de atuação, verdadeira e concretamente orientadas para esta sinergia, sob o risco de tornar a sobrevivência humana vítima de seus próprios atos. Educação Ambiental ou Educação para o Desenvolvimento Sustentável é, antes de tudo, educar para um profundo respeito e consciência ecológica sistêmica.

\section{Referências bibliográficas}

BRASIL. Constituição da República Federativa do Brasil. Disponível em http://www.planalto.gov.br/ccivil_03/constituicao/constituicao.htm. Acesso em: 10/07/2017

BRASIL. Plano Plurianual 2016-2019. Disponível em http://www.planejamento.gov.br/assuntos/planeja/plano-plurianual. Acesso em: 14/07/2017.

BRASIL. Ministério da Educação. Base Nacional Comum Curricular. Brasília, DF: MEC, 2015.2 Disponível em: http://basenacionalcomum.mec.gov.br/documento/BNCCAPRESENTACAO.pdf. Acesso em: 1\%/07/2017.

BRASIL. Ministério da Educação. Diretrizes Curriculares Nacionais Gerais da Educação Básica. Brasília: 2013. 562p. 


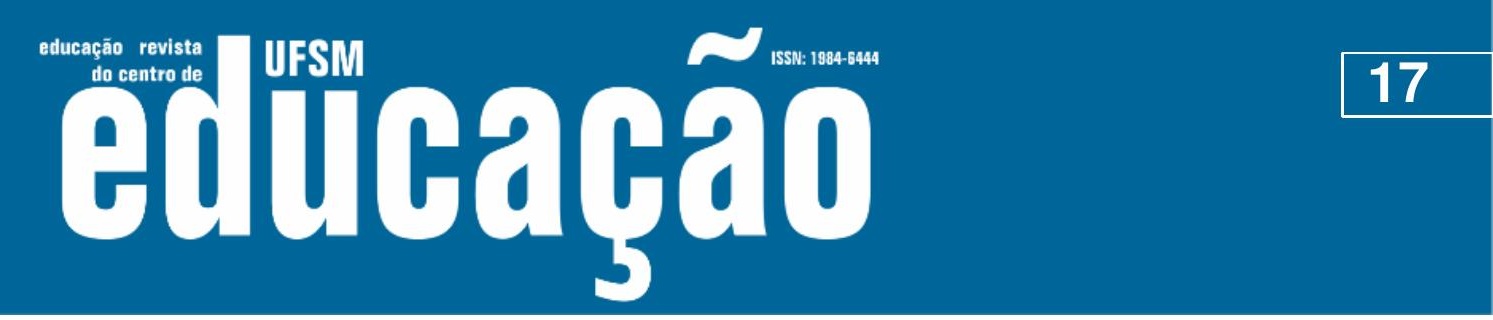

ISSN: 1984-6444 | http://dx.doi.org/10.5902/1984644436261

BRASIL. Ministério do Meio Ambiente. Programa Nacional de Educação Ambiental (Pronea). Brasília, DF: MMA, 2005, 52p.

BRASIL. Lei no 9.795, de 27 de abril de 1999. Dispõe sobre a Educação Ambiental, institui a Política Nacional de Educação Ambiental e dá outras providências. Disponível em http://www.planalto.gov.br/ccivil_03/leis/L9795.htm. Acesso em: 10/07/2017.

BRASIL. Lei n. 9.394/96 - Lei de Diretrizes e Bases da Educação Nacional. Disponível em: http://www.planalto.gov.br/ccivil_03/Leis/L9394.htm. Acesso em: 10/07/2017.

BRASIL. Lei 13.005. Aprova o Plano Nacional de Educação e dá outras providências. Disponível em http://www.planalto.gov.br/ccivil_03/_ato20112014/2014/lei//13005.htm. Acesso em: 16/07/2017.

BRASIL. Ministério da Educação. Plano Nacional de Educação. Lei n. 10.172/2001. Disponível em: http://portal.mec.gov.br/arquivos/pdf/pne.pdf. Acesso em: 10/07/2017.

BASTOS, Alexandre Marucci; DE SOUZA LEMES, Sebastião. A educação para o desenvolvimento sustentável no contexto curricular da rede pública de ensino do governo do estado de São Paulo: uma breve reflexão pela perspectiva da década da educação para o desenvolvimento sustentável da UNESCO (2005-2014). Revista on line de Política e Gestão Educacional, n. 19, 2015. Disponível em http://seer.fclar.unesp.br/rpge/article/view/9382. Acesso em: 12/07/2017.

BRUNDTLAND, Gro Harlem (Org.) Nosso futuro comum. Rio de Janeiro: FGV, 1987.

CAMBOIM, Jackeline Fernanda; BARBOSA, Adauto Gomes. Estratégias de educação ambiental por meio da atuação da COM-VIDA: vivências em uma escola do RecifePE. HOLOS, [S.I.], v. 1, p. 124-136, mar. 2012. ISSN1807-1600. Disponível em: http://www2.ifrn.edu.br/ojs/index.php/HOLOS/article/view/780. Acesso em: 23/09/2018.

CAPRA, Fritjof. O Ponto de Mutação: A Ciência, a Sociedade e a Cultura emergente. 23a ed. Trad. Álvaro Cabral. São Paulo, SP: Editora Pensamento-Cultrix Ltda, 2002.

CIAVATTA, Maria. A formação integrada: a escola e o trabalho como lugares de memória e de identidade. Trabalho Necessário, v. 3, n. 3, 2005. Disponível em: http://www.uff.br/trabalhonecessario/images/TN_03/TN3_CIAVATTA.pdf. Acesso em: 01/07/2017.

DA CUNHA SANTOS, Lucimara; DA SILVA, Rejane Maria Ghisolfi; PEDROSA, Maria Arminda. Práticas de Educação para o Desenvolvimento Sustentável: contribuições, limitações e possibilidades futuras. Indagatio Didactica, vol. 8(1), julho 2016. Disponível em http://revistas.ua.pt/index.php/ID/article/view/3872. Acesso em 23/09/2018. 


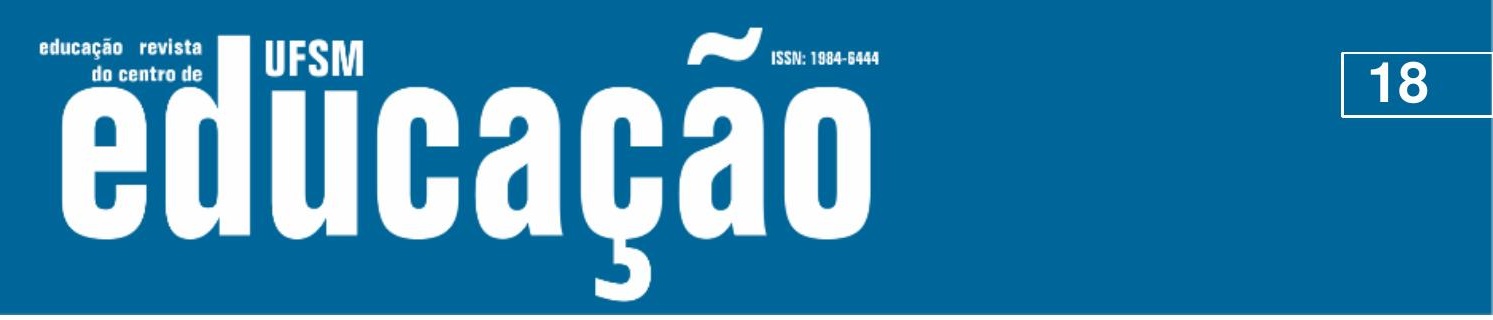

ISSN: 1984-6444 | http://dx.doi.org/10.5902/1984644436261

DINIZ, Eliezer M.; BERMANN, Celio. Economia verde e sustentabilidade. Estudos Avançados, São Paulo, v. 26, n. 74, p. 323-330, 2012. Disponível em http://www.s

cielo.br/scielo.php?script=sci_arttext\&pid=S010340142012000100024\&lng=en\&nrm= iso. Acesso em: 24/10/2016.

FREIRE, Ana Maria. Educação para a Sustentabilidade: Implicações para o Currículo Escolar e para a Formação de Professores. Pesquisa em Educação Ambiental, 2(1), 141-154, 2007.2 Recuperado de http://www.pos.ajes.edu.br/arquivos/referencial_20120913100933.pdf. Acesso em 10/07/2017.

FREITAS, Mário. A década de educação para o desenvolvimento sustentável: do que não deve ser ao que pode ser. Diretório de documentos sobre a Década da Educação para o Desenvolvimento Sustentável - Ministério do Meio Ambiente. $2006 . \quad$ Disponível em http://www.mma.gov.br/port/sdi/ea/deds/arqs/mariofreitas_edsfe.pdf. Acesso em: 12/07/2017.

GADOTTI, Moacir. Educar para Sustentabilidade: Uma contribuição à Década da Educação para o Desenvolvimento Sustentável. São Paulo: Editora e Livraria Instituto Paulo Freire, 2008. 127 p. (Série Unifreire, 2).

GADOTTI, Moacir. Pedagogia da práxis. Ministério do Meio Ambiente - Formação de Educadoras(es) Ambientais e Coletivos Educadores. 2005, pp. 237-244.

GÓMEZ, José Antonio Caride. In the Name of Environmental Education: words and things in the complex territory of education-environment-development relations. Policy Futures in Education, vol. 3, n- 3, 2005, p. 260-270. Disponível em http://journals.sagepub.com/doi/pdf/10.2304/pfie.2005.3.3.4. Acesso em 23/09/2018.

LAYRARGUES, Philippe Pomier. Educação Ambiental no Brasil: o que mudou nos vinte anos da Rio 92 à Rio+20. ComCiência - Revista eletrônica de jornalismo científico. 2012. Disponível em: http://www.comciencia.br/comciencia/?section=8\& edição $=75 \& i d=938$ Acesso em: 10/07/2017.

LEMOS, Pedro B. Silva; SALDANHA NETO, Canuto D; XAVIER, Antônio R. A política nacional de educação ambiental (lei no 9.795/1999) e a legalização da educação ambiental no ensino formal. Revista de Educação Ambiental (Online). Disponível em http://www.revistaea.org/pf.php?idartigo=2771. Acesso em: 10/07/2017.

MARTINE, George; ALVES, José Eustáquio Diniz. Economia, sociedade e meio ambiente no século 21: tripé ou trilema da sustentabilidade? Revista brasileira de estudos de população, São Paulo, v. 32, n. 3, p. 433-460, Dezembro de 2015. Disponível em http://www.scielo.br/scielo.php?script=sci_arttext\&pid=S0102$30982015000300433 \&$ Ing=en\&nrm=iso. Acesso em 23/10/2016. 


\section{T usm Autlatha}

ISSN: 1984-6444 | http://dx.doi.org/10.5902/1984644436261

ONU BR- ORGANIZAÇÃO DAS NAÇÕES UNIDAS NO BRASIL. A Agenda 2030 para - Desenvolvimento Sustentável. Disponível em https://nacoesunidas.org/ pos2015/agenda2030/. Acesso em: 13/09/2016.

PEREIRA, Leandro Angelo; ROCHA, Rosana Moreira da. Mariculture and Economic, Social and Environmental Bases that Determine Development and Sustainability. Ambiente e sociedade, São Paulo, v. 18, n. 3, p. 41-54, Sept. 2015. Disponível em http://www.scielo.br/scielo.php?script=sci_arttext\&pid=S1414753X2015000300004\&lng=en\&nrm=iso. Acesso em: 14/07/2017.

PÉREZ, José Gutiérrez; LLORENTE, Maria Teresa Pozo. Stultifera Navis: institutional tensions, conceptual chaos, and professional uncertainty at the beginning of the Decade of Education for Sustainable Development. Policy Futures in Education, v. 3 , n. 3, p. 296-308, 2005. Disponível em http://journals.sagepub.com/doi/pdf/10.2304/pfie.2005.3.3.7. Acesso em 23/09/2018.

SACHS, Ignacy. Ecodesenvolvimento - Crescer sem Destruir. São Paulo: Vértice, 1986.

SACHS, Ignacy. Estratégias de transição para o século XXI: desenvolvimento e meio ambiente. São Paulo: Studio Nobel - FUNDAP. 1993.

SAVIANI, Dermeval. Trabalho e educação: fundamentos ontológicos e históricos. Revista Brasileira de Educação, Campinas, v.12, n.32, p. 52-180, jan./abr. 2007. Disponível em: http://www.scielo.br/pdf/rbedu/v12n34/a12v1234.pdf. Acesso em: 01/07/2017.

SAUVÉ, Lucie. Educação Ambiental e Desenvolvimento Sustentável: uma análise complexa. Revista de Educação Pública, vol. 10, jul/dez, 1997 Disponível em http://www.ufmt.br/revista/arquivo/rev10/educacao_ambiental_e_desenvolvim.html. Acesso em 15/07/2017.

UNESCO. Organização das Nações Unidas para a Educação, a Ciência e a Cultura. Década da educação das Nações Unidas para um desenvolvimento sustentável, 2005-2014: documento final do esquema internacional de implementação. Brasília: UNESCO, 2005.2 Disponível em: http://unesdoc.unesco.org/images/0013/001399/139937por.pdf. Acesso em: 12/07/2017.

UNESCO. Educação para o desenvolvimento sustentável. Disponível em http://www.unesco.org/new/pt/brasilia/education/education-for-sustainabledevelopment/\#c155001. Acesso em 14/07/2017 


\section{$\sim$

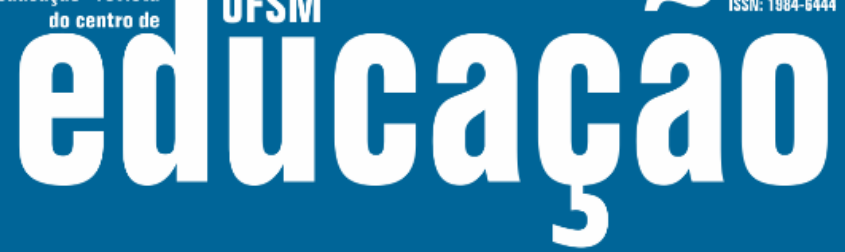

ISSN: 1984-6444 | http://dx.doi.org/10.5902/1984644436261

\section{Correspondência}

Carlos Eduardo Marques da Silva e Dra. Simone Ferreira Teixeira - Universidade de Pernambuco - Faculdade de Ciências da Administração e Direito - Av. Sport Clube do Recife, 252 - CEP 50750-500, Madalena, Recife, Pernambuco, Brasil.

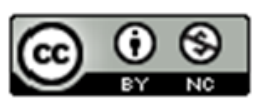

This work is licensed under a Creative Commons Attribution-NonCommercial 4.0 International (CC BY-NC 4.0) 